\title{
Table of treaties and conventions
}

Berne Convention for the Protection of Literary and Artistic Works,

1971

arts 1-21

art 6bis

art 9(2)

art 11bis(2)

art 13(1)

art 18

Appendix

Convention on Biological

Diversity

European Patent Convention

21, 22, 23, 30, 31-2, $37,39,67,68,100$

International Convention for the

Protection of New Varieties of

Plants

Marrakesh Agreement establishing the WTO, Annex 1C see TRIPS Agreement

Marrakesh Agreement establishing the WTO, Annex 2 - Legal Instruments

Paris Convention for the Protection of Industrial Property, 1967 $12,17,18,19,41,67,68,77$, 100, 195

art 4 17

art 6bis

art 6 bis (2)

art 6ter

art 10bis

art 11

art 16(2)

art 16(3)

art 62(3)

22, 38

23

23

40

31

70

51

43,44

16

18

141

17
Rome Convention 1961

39, 40

TRIPS Agreement (Agreement on

Trade Related Intellectual

Property Rights), Annex 1C of

the Marrakesh Agreement

31, 32 Establishing the WTO, 1994

Part II

30

art 3

$30,102,176,200$

art 4

30, 200

art 7

$2,56,58,59,60,61$,

$68,70,208$

art 8

$56,58,59,68,70,83$

art $8(1)$

59

arts 9-13

30

art 9

31,32

art 9(2)

art 10

32

art 10.2

$32,33,34-5$

art 11

21

art 12

37

art $1322,37, \mathbf{3 8}, \mathbf{3 9}, \mathbf{5 8}, \mathbf{6 0}, \mathbf{7 7}$

art 14

art 15

22, 30, 39, 41

art 15(1)

41-3

art 16

16,18

art 16(2)

$43,44,176$

art 17

17

45,60

art 18

46

art 19

46

art 20

46,47

art 21

47,48

art 24

176

16 art 26(2)

60,77

16 art 27

$48,49,50,56,76,77$

17 art 27(2)

50 
art 27(3)

art 28

art 29

art 30

art 31

art 31 bis

art 31(f)

art 31(L)(i)

art 32

art 33

art 34

art 39

art 40

art 41

art 41(1)

art 41(2)

art 41.4

art 43

art 44

art 45(1)

art 50

arts 50:1-4

arts 51-60

art 61

art 63

art 65

art 65(2)

art 65(4)
$51 \quad$ art 66(2)

$\mathbf{1 3}, \mathbf{5 1}, \mathbf{2 0 1}$ art 67

52 art 70(8)

52, 76, 77 art 70(9)

$53,54,55,56,74,205$

71, 76, 204, 205

201, 203

14

13,55

55

55

24,14

83

110

102,110

112

13, 18, 101

111

103

15,112

$14,15,19,23,163$

15

26

104, 110, 114

114,176

176

78

48,78

Annex 1986
Annex - Appendix

Shanghai Conference on

Intellectual Property Rights

(IPR), 2004

79, 208

79

48, 68

68

204-6

206

UPOV (Plant Varieties) Convention

Washington Treaty on Intellectual

51

Property in Respect of Integrated

Circuits, 1989

68

WIPO Copyright Treaty (WCT) 2,

28, 71, 72

WIPO Performances and

Phonograms Treaty (WPPT) 2,

28,40

WTO Agreement

art XVI:4

11

WTO Doha Declaration, 2001

(Declaration on the TRIPS

Agreement and Public Health) 7, $13,54,61,66,68,69,70,71$,

198-206

WTO Punta del Este Declaration, 
Paul Torremans, Hailing Shan, and Johan Erauw - 9781847207210 Downloaded from PubFactory at 04/26/2023 02:40:01PM via free access 